\title{
Forecast of a quality indicator in academic activity using statistical methods
}

\author{
Silvia Veresiu*, Elena Mereuta, Madalina Rus, Daniel Ganea, and Valentin Amortila \\ "Dunarea de Jos" University of Galati, Faculty of Engineering, Romania
}

\begin{abstract}
The paper presents the time evolution of an indicator for quality, which is related to self-evaluation of academic staff in technical faculties. The study is focused on two major issues that compose the academic activities: teaching and research activity on one side, and managerial activities on the other side. The aim of the study is to reveal the forecast of self-evaluation using statistical methods and to assess if possible, the minimum accepted value of the quality indicator.
\end{abstract}

\section{Introduction}

In the recent years, quality has become a higher education priority in universities all over the world.

The changes on the labor market and the rise of the institutions that provide higher education (private universities, increasing number of public universities, new study programs and specializations) determine the employers to ask for official validated information about the quality of education in the targeted institutions.

The official recognition is reflected by the accreditation obtained by the university itself. The national agency licensed to grant temporary authorization or accreditation performs the external evaluation of to the quality of the educational process by complying with the existent criteria.

The criteria of accreditation encourage the institutions of higher education to try innovative programs and procedures and to adopt them when they prove to be successful.

The higher education all over the world suffered major changes due to the permanent character of the changes occurred in the social, political and economic environment.

In order to fulfil the valid standards, the institutions of higher education must develop policies and procedures of quality assurance of the educational process. These must commit themselves explicitly to develop an education that recognized the importance of quality in their activity.

According to "The Methodology of External Evaluation, Standards and the List of Performance Indicators of ARACIS" [1], during the process of education's quality assurance, three issues are under focus: the institutional capacity, the educational efficiency and the management of quality.

The institutional capacity refers to: the university's organization on the basis of an integrated and well-structured management and to: the organization of the teaching -

${ }^{*}$ Corresponding author: silvia.veresiu@ugal.ro 
learning processes focused on the students, methods and techniques that allow the assimilation of knowledge measured by the outcomes learning and research; evaluation criteria of the students, the existence of a qualified teaching staff, the existence of available resources and learning facilities, of the services offered to the students.

The quality's management is focused on activities, strategies, techniques, structures, policies by means of which the university proves the permanent administration system; the existence of an infrastructure, of proper equipment, and well prepared and capable human resources able to achieve the aims.

The educational efficiency refers evaluation of the performances obtained in ensuring and improving the quality of the education they offer.

The evaluation of the three issues is performed using criteria and standards expressed by performance indicators. The criteria represent the basis of organizing and functioning of the educational institution. The performance indicators are tools for measuring the achievement of the work carried out by the university in question, in relation to the standards. These indicators can vary from the minimum level to the maximum one.

\section{Teaching staff assessment}

The quality of teaching staff is regularly assessed through the expertise, capacity for transmitting knowledge to students and professional ethics.

The evaluation criteria mentioned above, are summarized in an evaluation sheet that includes information from four topics: self-evaluation, peer review, assessment of students and evaluation of head department.

This paper refers only to the first issue, which is conducted annually, based on selfassessment forms.

The self-assessment sheet is approved by the Senate, is drawn up annually and represents a multi-criteria assessment of all teaching and research activities covered on the previous calendar year.

The self-assessment sheet includes two parts:

A. Criteria for assessing the teaching and research activities and promotion criteria,

B. Other criteria (professional, administrative, cultural).

The A set of criteria represents the elementary performance criteria according to ARACIS standards, the performance indicators to measure the level of scientific research, according to National Council of Scientific Research, and criteria for annually financing the higher education institutions. The A set of criteria form the basis of professional promotion [2]. The sets of criteria A and B are the basis for granting the performance rewards.

Completion and submission of the self-evaluation sheet in compliance with deadlines shows that the entire teaching staff has acquired and developed a culture of quality according to the requirements of a total quality management.

The paper aims to study the evolution of the scores recorded for self-assessment criterion $\mathrm{A}$ in the schedule for all teaching positions in two technical faculties. Also, considering the results statistical methods will be used for converting a quantitative indicator into a qualitative one.

\section{Research methods}

Two statistical instruments were used as research methods: the moving average [3-4] and the stochastic oscillator [5-6].

The first method was used to analyze the collected data between 2008 and 2016. The annual scores were systematized and thus time series were generated. 
The moving average method consists of calculating the seasonal component of time series by dividing the trend to total successive values of the series. The method is used when a time series shows fluctuations, in order to smooth the evolution. The moving average method aims at highlighting the central tendency of evolution of a phenomenon. The method is characterized by elasticity, the ability to easily adjust to new conditions. Using regression the basic trend of evolution of the studied phenomenon is established, by cancelling large fluctuations, which may distort real evolution. [7]

The averages are called mobile because constantly the first term of the previous average is deleted, while the next term is added.

Thus, based on average annual recorded scores from self-assessment files, criterion A, seasonal component, irregular component and the trend component were calculated and the combination of them determined the forecast for the next three years. [8]

Using stochastic oscillator is imported from financial analysis. It can provide information on the stability of the market, determining the actions of those operating in the market. In this paper, the stochastic oscillator is used as an indicator of the equilibrium state, providing stability range, with which one can determine the maximum and minimum values of the self-assessment scores.

The stochastic oscillator is represented by two lines: $\% \mathrm{~K}$ and $\% \mathrm{D}$, where $\% \mathrm{~K}$ is the main line, and $\% \mathrm{D}$ is a moving average of $\% \mathrm{~K}$.

The $\% \mathrm{~K}$ line is computed using the formula (1):

$$
\% K=\frac{C-L_{n}}{H_{n}-L_{n}} 100
$$

Where: $\mathrm{C}$ is the annual score;

$\mathrm{L}_{\mathrm{n}}$ is the minimum score from the last three years;

$\mathrm{H}_{\mathrm{n}}$ is the maximum score of the last three years.

The $\% \mathrm{D}$ line is computed using the formula (2):

$$
\% D=\frac{H_{3}}{L_{3}} 100
$$

Where: $\mathrm{H}_{3}$ is the sum of the value C- $\mathrm{L}_{\mathrm{n}}$ for the last three years; $\mathrm{L}_{3}$ is the sum of the $\mathrm{H}_{\mathrm{n}}-\mathrm{L}_{\mathrm{n}}$ for the last three years.

\section{Results and discussions}

For this study the average scores of each teaching staff category from two technical faculties (criterion A) were considered (table 1). The scores were normalized so that the number of teachers (time-varying) should not distort the study.

Table 1. Average scores of self-evaluation records.

\begin{tabular}{|c|c|c|c|c|c|c|c|c|}
\hline \multirow{2}{*}{ Year } & \multicolumn{4}{|c|}{ Technical faculty 1 } & \multicolumn{4}{c|}{ Technical faculty 2 } \\
\cline { 2 - 9 } & Prof. & As.prof. & Lecturer & Assist. & Prof. & As.prof. & Lecturer & Assist. \\
\hline 2008 & 993.62 & 840.65 & 316.49 & 151.22 & 546.16 & 252.59 & 110.00 & 120.16 \\
\hline 2009 & 1304.87 & 825.00 & 543.39 & 289.98 & 1068.76 & 337.38 & 182.17 & 173.73 \\
\hline 2010 & 2021.07 & 822.75 & 610.28 & 457.68 & 1902.62 & 925.18 & 334.43 & 466.60 \\
\hline 2011 & 1849.88 & 923.13 & 732.14 & 456.47 & 1962.90 & 1116.30 & 324.80 & 145.50 \\
\hline 2012 & 1613.29 & 1000.40 & 708.81 & 712.82 & 2137.18 & 976.29 & 548.15 & 670.64 \\
\hline
\end{tabular}




\begin{tabular}{|l|l|l|l|l|l|l|l|l|}
\hline 2013 & 1139.90 & 462.64 & 474.38 & 327.47 & 1844.47 & 770.24 & 687.98 & 297.19 \\
\hline 2014 & 1228.53 & 762.35 & 492.82 & 381.20 & 2193.01 & 606.93 & 782.28 & 455.18 \\
\hline 2015 & 1074.19 & 791.55 & 485.31 & 437.24 & 2307.80 & 968.69 & 806.82 & 274.09 \\
\hline 2016 & 1184.28 & 784.38 & 484.82 & 515.00 & 2307.99 & 1230.81 & 768.41 & 350.53 \\
\hline
\end{tabular}

The data were computed using the moving average method. The figures 1-4 present the historical evolution of average scores, the center moving average (CMA) (the baseline) and the forecast for the following three years, for all categories of teaching staff.

The intermediate results showed that it is possible to emphasize the seasonality irregularity components, to reveal the seasonality components and to predict the future trends for the average score, getting rid of irregularities and seasonality. For example, for the average score of professors from the first technical faculty, the seasonality irregularity was in 2009 24\% below the baseline (CMA), while in 2012 was 6\% above the baseline (fig.1 a). The seasonality components are below the smooth outline (CMA) (fig.1a). For the second technical faculty, the results revealed that the seasonality irregularities components were 14\% above the baseline (in 2016), and 18\% below the baseline, in 2009 (fig. 2b). Regarding the seasonality components, they were $8 \%$ above the baseline in 2010 and $2 \%$ below the smooth outline in 2011 (fig.1b). The same analysis can be performed for all categories of teaching staff: associate professors, lecturers, assistants (fig. 2-4).

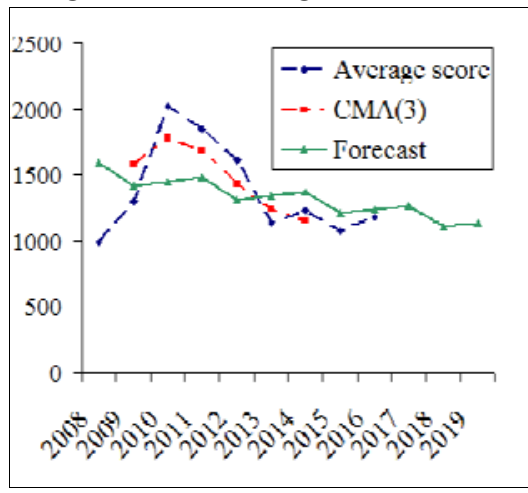

a) faculty 1

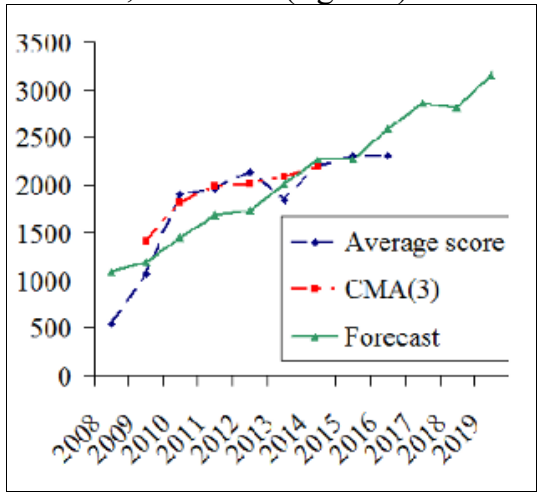

b) faculty 2

Fig. 1. Forecast of professors 'average scores.

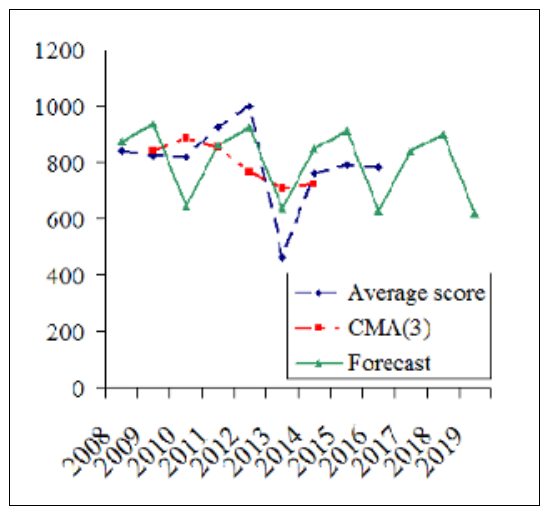

a) faculty 1

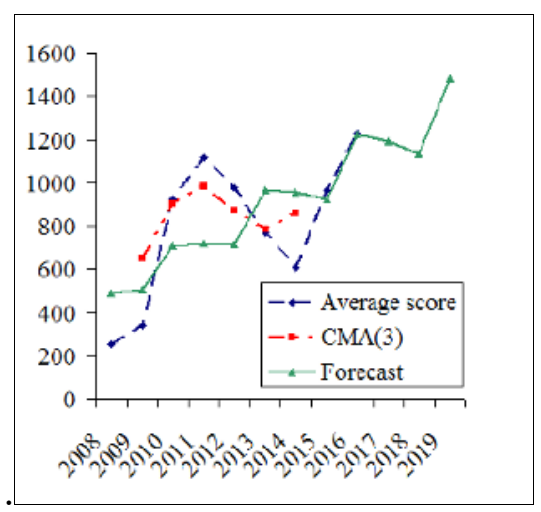

b) faculty 2

Fig. 2. Forecast of associate professors 'average scores. 


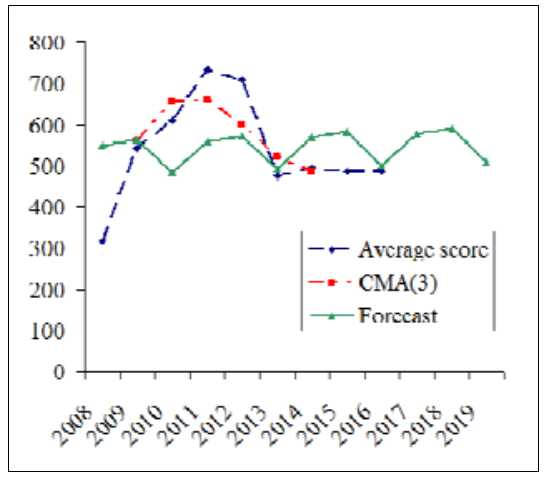

a) faculty 1

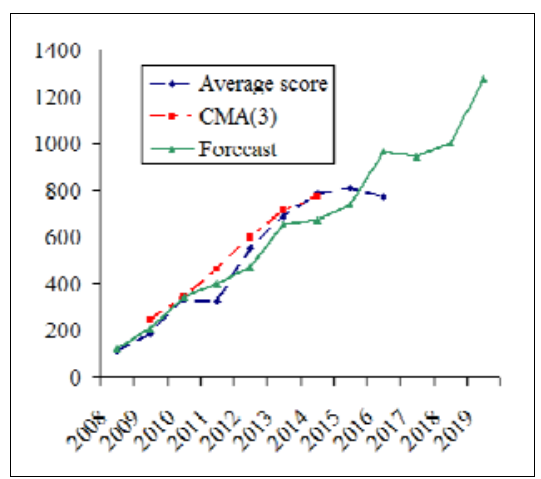

b) faculty 2

Fig. 3. Forecast of lecturer 'average scores.

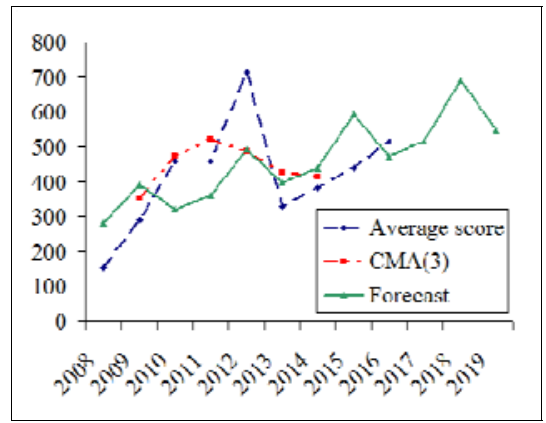

a) faculty 1

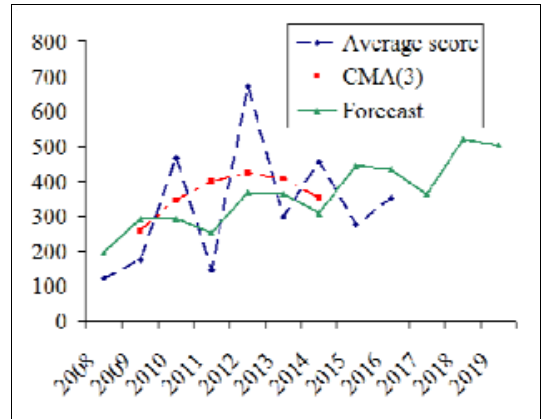

b) faculty 2

Fig. 4. Forecast of assistants 'average scores.

After determining the forecast of average scores, the next step consists of determining the stability interval for the average score, for the next three years. In order to achieve this goal, the stochastic oscillator method is used (fig. 5). This method provides the maximum and minimum values of the average score, for the next cycle of three years. These values are the extreme values from the stability range $[20 \%, 80 \%]$. Thus, the $\% \mathrm{~K}$ line is the taken into account and all the values outside this range are considered extreme and neglected. The analysis revealed the fact that for the professors' in faculty 1, the range for average scores is: [331, 674], while for the professors in faculty 2, the range is [915, 2162] (fig.6).

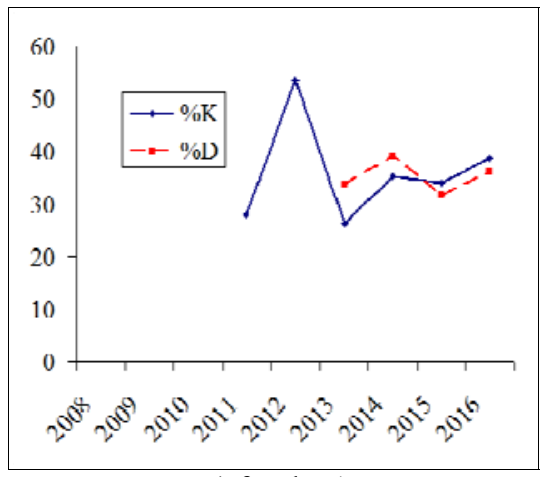

a) faculty 1

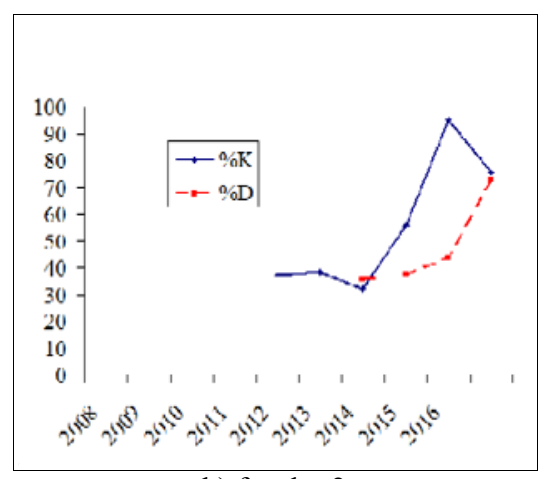

b) faculty 2

Fig. 5. Stochastic oscillator for the professor's average score. 


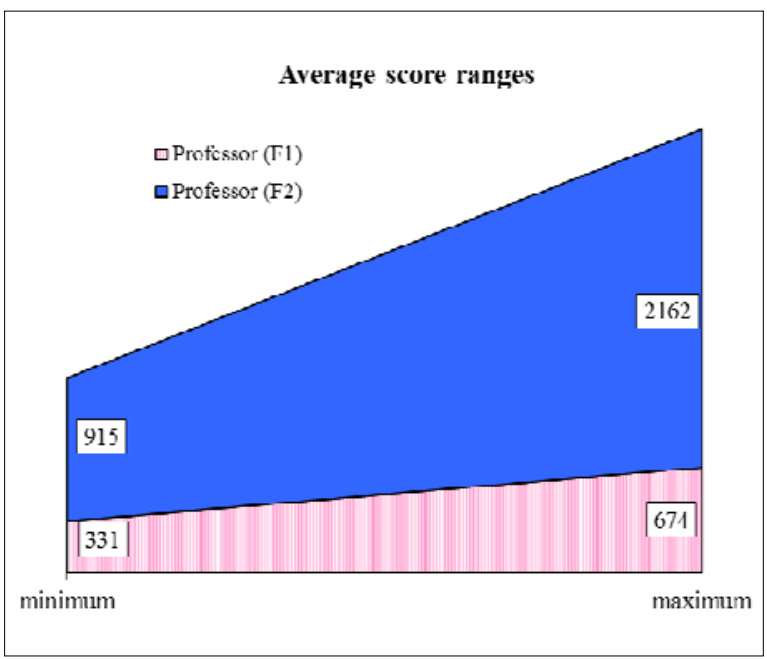

Fig.6. Average score ranges for professor.

The same analysis can be performed for all categories of teaching staff. The teaching and research activities can be assessed now using ratings. If the score is below the minimum value, the rating is insufficient. For a score between the minimum and maximum value, the rating is good and for the score above the maximum value, the rating is very good.

\section{Conclusions}

Based on the forecasts provided by the moving average method and the stochastic oscillator, it is possible to set limits for rating each category of teaching staff.

This approach led to a qualitative assessment, starting from a quantitative expression of the annual performances.

It is important to perform the same analysis for each faculty or department, even if they are technical ones.

The study can be extended to all faculties, humanities, arts, economic, medical etc.

\section{References}

1. *** External evaluation methodology, standards, reference standards and list of performance indicators, (www.aracis.ro/proceduri/)

2. *** Annual evaluation for teachers (http://www.qa.ugal.ro/index.php?page=evaluare)

3. C. Anghelache, Theoretical and economical statistics guide, Ed. Economica, Buc., (2008)

4. E. Biji, et al., Statistics for economists, Ed. Economică, Bucuresti, (2012)

5. G. C. Lane, Getting Started With Stochastics,3 (1998)

6. D. Zapodeanu, D. Popa, Annales Universitas Apulensis, Univ. "1 Dec. 1918" Alba Iulia, issue. 8, vol. 2, 316-321 (2006)

7. C. Anghelache, G. C. Anghelache, F. P. C. Lilea, A. G. Baltac, Romanian Journal of

Statistics issue. 8, 4-15 (2012)

8. https://www.oanda.com/forex-trading/learn/technical-analysis-fortraders/stochastic/lines 